\title{
Flexural behavior of engineered cementitious composite (ECC) slabs with polyvinyl alcohol fibers
}

\author{
Shwan H. Said, Hashim Abdul Razak*, Ismail Othman \\ StrucHMRS Group, Dept. of Civil Engineering, Faculty of Engineering, University of Malaya, 50603 KL, Malaysia
}

H I G H L I G H T S

- Study on compressive and flexural strength of engineered cementitious composites.

- For ECC mixes, when reinforcing index increases, the compressive strength decreases.

- PVA slabs did not attain the desired ductility due to rupture in PVA fibers.

- New definition as an extension to ASTM C 1018 was proposed for ECC PVA.

- Increase in residual strength factors indicates a higher amount of strength retained.

A R T I C LE I N F O

Article history:

Received 1 April 2014

Received in revised form 8 August 2014

Accepted 22 October 2014

Available online 27 November 2014

\section{Keywords:}

Engineered cementitious composite (ECC)

Polyvinyl alcohol fibers (PVA)

Fiber content

Aspect ratio (A.R)

Reinforcing index (R.I.)

Deflection at failure

Residual strength factor

Post-cracking strength

ASTM C 1018

\begin{abstract}
A B S T R A C T
This paper investigates the effects of polyvinyl alcohol (PVA) fibers on the toughness, compressive and flexural strength of engineered cementitious composite (ECC) cubes and slabs. The key parameter discussed in this study is the reinforcing index. To evaluate the strain-hardening behavior of ECC with different PVA fiber contents, tests were conducted in direct tension. Flexural toughness was also evaluated following ASTM C 1018 procedure and post-cracking strength technique $\left(\mathrm{PCS}_{m}\right)$. Results showed that the compressive strength decreases as the reinforcing index increases in a nonlinear trend. By increasing the reinforcing index, the first crack load decreases and ultimate strength slightly increases. Furthermore, a significant increase in the first crack strength was obtained by an excess value 1000 of the reinforcing index. There is a significant increase in the deflection at ultimate load and the deflection at failure as the reinforcing index increases in a linear manner. The strain-hardening and multiple cracking behavior were observed for slabs with reinforcing indices higher than 316 whereas the softening behavior was observed for lesser values. The ECC PVA slabs did not attain the desired ductility due to the rupture of PVA fibers. A significant increase has occurred to the toughness indices $I_{20}, I_{30}$ and $I_{40}$ with the increase in reinforcing index. Moreover, the indices exceed the limitations considered. A new definition as an extension to the definition given in ASTM C 1018 was proposed for ECC PVA material according to the observed results. All the residual strength factors increased as the reinforcing index increases which indicates a higher amount of strength retained. The PCS $_{60}$ values increased with increase in the reinforcing indices. Thus, the increase in PCS $_{60}$ values indicates higher flexural performance, better ductility and energy absorption capacity for slabs.

(c) 2014 Elsevier Ltd. All rights reserved.
\end{abstract}

\section{Introduction}

Since the 19th century, many attempts were made by researchers to incorporate steel fibers in concrete [1], such as iron wires, granular iron wastes and annular steel fibers, in order to improve concrete strength against cracks, fatigue, and shrinkage.

This prompted various researchers to carry out studies on stee fiber reinforced concrete (SFRC) in the early 70's [2-5]. Subse-

\footnotetext{
* Corresponding author. Tel./fax: +60 379675233 .

E-mail address: hashim@um.edu.my (H.A. Razak).
}

http://dx.doi.org/10.1016/j.conbuildmat.2014.10.036 0950-0618/@ 2014 Elsevier Ltd. All rights reserved. quently, it became apparent that the steel fibers effectively improve concrete ability to withstand flexure, tension, shear, abrasion, fatigue, freezing and thawing cycles, impact and cyclic loading. Furthermore, steel fibers arrest the crack widths and prevent propagation of cracks throughout the hardened concrete. In addition, steel fibers intrinsically increase the ductility of concrete resulting in improved energy absorption characteristics, and increase its ultimate tensile strain, as well as its fracture tensile strain at failure. Unlike the conventional concrete, the softening tail of the tensile stress-strain curve for steel fiber composites descends gradually with no sudden drop in stresses after first 
cracking. The amount of tensile strain at failure will be of several orders greater than the corresponding value as compared to the conventional concrete.

Despite all the advantages of steel fibers stated above, the designers of steel fiber composites have encountered a series of problems which prevent them from preparing homogeneous and rheological mixes. One of the problems faced is the difficulty in preparing a steel fiber composite at higher fiber content i.e. $2 \%$ and more, using higher aspect ratio of 100 or more, and using maximum size of coarse aggregate more than $5 \mathrm{~mm}$ [6]. This would lead to the phenomenon of balling which causes irregular dispersion of fibers ultimately producing vulnerable and inhomogeneous mix. Additionally, steel fibers possess a considerably high specific gravity compared to other ingredients, which prevents the discrete short steel fibers from dispersing equally throughout the mix. Finally, the steel fibers in hardened composite stand the risk of corrosion if the hardened concrete is exposed to saline or acidic environment. Such corrosion leads to deterioration of SFRC strength and toughness [7].

\section{Engineered cementitious composite (ECC)}

Engineered cementitious composite (ECC) or bendable concrete or self-healing concrete, is a class of improved high performance fiber reinforced cementitious composite (HPFRCC), was introduced in the early 90 's, [8]. It is characterized by a tensile strain-hardening and multiple-cracking behavior [9]. In contrast to conventional concrete, ECC has a tensile strain capacity in the range of 3-7\% compared to a value of $0.01 \%$ for conventional concrete [ 10 ]. In order to attain extremely high ductile ECC with addition of small fiber content of $2 \%$ or less, it is recommended to achieve the underlying principles stated thus. Firstly, elimination of the usage of coarse aggregates [11] and using fine silica sand with maximum particle size of $200 \mu \mathrm{m}$ [12] and secondly, adding discrete short fibers having diameter of several tens of microns. Thus, filament polymeric fibers are the most suitable fibers having such a diameter.

Micromechanical material design is the most convenient approach employed to prepare high bendable composite. It is the micromechanical model which is employed to describe the formation of synergistic mechanical interactions between fiber, matrix and interface, as well as to optimize the microstructure of the composite [13]. These properties allow ECC to withstand tensile flexural and shear loads as well as to increase its ductility. The tensile stress-strain curve is analogous to that of a ductile metal. At compression behavior, and due to the absence of coarse aggregates in ECC, the elastic modulus will be lesser than that of conventional concrete resulting in more strain when it attains its compressive strength. The softening tail of compressive stressstrain curve will descend in a gradual manner more than conventional concrete that is, less inclined achieving higher deformation.

The ductile behavior allows ECC to create numerous of closely spaced microcracks with very specific width. Due to its microcracking behavior, ECC is highly durable, that is, corrosion resistance and resistance to the penetration of aggressive liquids [14 ECC has the property of self-healing, whereby the unreacted cementitious particles after cracking and exposed to hydration create a cementitious product, which will extend and fill the cracks having specific widths [15].

In the literature, prisms were commonly used in the tests to evaluate the flexural behavior of fiber composite. In this study, slabs were considered using ECC PVA material to investigate the flexural behavior in different parameters such as slab strength at first crack stage and post-cracking stage, slab deflection at first crack stage, slab deflection at ultimate load stage and failure stage, crack pattern and propagation, evaluation of toughness using ASTM C 1018 and post-cracking strength technique (PCS $\left.{ }_{m}\right)$. Direct tensile test was conducted on PVA mixtures to evaluate the strainhardening behavior with different reinforcing indices, to set the cut-off point and specify the reinforcing index at which the ECC is applicable, and to recognize the strain-hardening effect in both direct tension and flexural tests and compare between them.

\section{Review of past studies}

Many research works have been conducted on fiber reinforced cement composites FRCC and ECC. Li and Wang [16] conducted a study to highlight the flexural behavior of ECC beams reinforced with glass fiber-reinforced polymer (GFRP). Results showed that using the same reinforcement details, ECC beams demonstrate increase in ductility, deformation, flexural strength, shear resistance, and damage tolerance compared to high-strength concrete (HSC) beams. In addition ECC beams without stirrups, exhibit higher shear resistance than HSC beams having shear reinforcements.

Fischer and Li [17] conducted an experimental study on flexural load-deflection behavior of fiber-reinforced polymer (FRP) reinforced ECC members under reversed cyclic loading conditions. Results indicated that the interaction of elastic FRP reinforcement and ECC with ductile behavior leads to nonlinear elastic behavior of load-deflection curve. Furthermore, compatible deformation between reinforcement and ECC results in high interfacial bond, removal of interfacial bond stress, elimination of relative interfacial slip and prohibiting the composite failure by bond splitting and spalling of ECC cover. Finally, FRP reinforced ECC members did not possess meaningful energy absorption capacity compared with conventional steel reinforced members.

Neela [18] investigated the flexural behavior of ballast FRP bar reinforced concrete members with polypropylene fibers (PP). Results showed that the addition of PP fibers leads to an increase in shear strength, toughness, and compressive strain. The results also showed a reduction in compressive strength, deflection and the ductility of PP reinforced slabs. The amount of energy absorption for concrete slabs reinforced with PP fibers is equal to that of slabs without fibers.

Balaguru et al. [19] conducted an experimental study to evaluate the flexural toughness of steel fiber reinforced concrete (SFRC). Results showed that indices at higher deflection, such as $I_{50}$ and $I_{100}$ are good indicators and should be computed for the evaluation of FRC. Hooked-end fibers with fiber content in the range of 0.385$0.77 \%$ are adequate for presenting better toughness and ductility whereas the length effect does not influence the toughness. In order to improve the toughness in high strength concrete, higher fiber content is therefore required. Also, $1.54 \%$ of steel fibers are needed in mix containing $20 \%$ silica fume to obtain significant ductility.

Long et al. [20] to investigated the effect of mix proportion on flexural toughness of ECC with PVA fibers. The results indicated that the increment in water reducer results in reduced flexural capacity and toughness. Besides, the increase in fiber content should be over $2 \%$ to develop a significant increase in flexural ductility and toughness due to the bridging of cracks. Moreover, higher amount of sand leads to reduced ductility and toughness. Thus, the best ratio of sand to be used in ECC to obtain better flexural toughness and ductility is 0.2 .

\section{Flexural toughness of ECC slabs}

\subsection{Toughness estimation based on ASTM C 1018}

In order to estimate the flexural performance and the amount of energy absorption of ECC slabs, an ASTM C 1018 [21] standard test method to determine the toughness and toughness indices for FRC 
was followed. Some relative values called "toughness indices" express the flexural performance and indicate the degree of ductility and energy absorption capacity up to a specified value of deflection and the ability of ECC slabs to deflect freely without any sudden failure. The evaluation of toughness indices depends on knowing the first-crack load and first-crack deflection values which necessitate determining them accurately on load-deflection curve. According to ASTM C 1018 definition, toughness index is the ratio of the area under load-deflection curve up to limited deflection value, to the area up to the deflection established at first crack as indicated in the following expression.

$I_{T}=$ Area under (load-deflection) curve up to limited deflection valve Area under (load-deflection) curve up to first crack deflection $\delta$

If $T=5$, the toughness index $I_{5}$ is equal to the ratio of area under the curve up to a deflection corresponding to three times the first crack deflection $(3 \delta)$ to the area up to first crack deflection. Similarly, the toughness indices $\mathrm{I}_{10}$ and $\mathrm{I}_{20}$ are calculated as the quotient of area under the load-deflection curve up to5.5 $\delta$ and $10.5 \delta$ to the area up to the first crack deflection respectively. For brittle materials, the toughness index equal to 1 .

The size of area obtained under the load-deflection curve is a direct measure of the flexural toughness and the ability of ECC slab to absorb energy and to attain higher ductility. Thus, the higher amount of toughness (or area under load-deflection curve), the higher ductility and energy absorption capacity.

ASTM allows for the evaluation of toughness indices $I_{30}, I_{40}$ or more corresponding to area up to deflections $15.5 \delta, 20.5 \delta$ or more respectively. The higher the subscript $T$ value of reinforcing index for testing beam or slab sample, the higher the flexural toughness and energy absorption capacity. The toughness index value $I_{T}$ is a cumulative number of its predecessor one $I_{S}$, where $T>S$, plus the additional value determined from the area bounded between the corresponding deflection values for $I_{S}$ and $I_{T}$. For elastic-perfectly plastic materials, $I_{5}=5, I_{10}=10, I_{20}=20$ and so on. In this paper and according to the load-deflection results, it is convenient to discuss the variation of toughness indices $I_{5}, I_{10}, I_{20}, I_{30}$ and $I_{40}$

Residual strength factor represents the amount of strength retained at the post-cracking stage within a specific interval as a percentage of the first crack strength. It is a measure to sustainability of beam or slab within a specific loading stage. The general formula for estimating the residual strength factor between two indices $I_{T}$ and $I_{S}$ is as follows:

$R_{S, T}=N\left(I_{T}-I_{S}\right) \quad T>S$

where $N=100 /(T-S)$.

If $S=5$ and $T=10$ then $N=20$ and $R_{5,10}=20\left(I_{10}-I_{5}\right)$.

If $S=10$ and $T=20$ then $N=10$ and $R_{10,20}=10\left(I_{20}-I_{10}\right)$ and so on.

For brittle materials, the residual strength factor equal zero. However, for elastic-perfectly plastic materials, the $R$ factors equal 100 . In this paper, $R_{5,10}, R_{10,20}, R_{20,30}$ and $R_{30,40}$ were discussed and considered according to the type of toughness indices considered.

4.2. Toughness estimation of ECC slabs based on post-cracking strength $\left(\mathrm{PCS}_{m}\right)$ technique

A technique was proposed by Banthia and Trottier [22] to estimate the flexural toughness and energy absorption capacity was applied in this work. In this methodology, locating the point where first-crack occurs on load-deflection curve which leads to estimation of human errors is unnecessary. However, this technique is based on finding the point of peak load on the curve. For the composites of strain hardening and multiple cracking characteristics (as the majority of ECC testing slabs), the peak load point represents the capacity of hardened mortar before the fiber mechanism action commence. At this point, the area under load-deflection curve should be divided into two regions; the pre-peak region which is specified before the peak load location and the post-peak region which is specified after the peak load location as indicated in Fig. 1. The toughness is evaluated by calculating the post-cracking strength according to this technique from the following formulae,

$$
\mathrm{PCS}_{m}=\frac{A_{\text {post }, m} \cdot L}{\left(\frac{L}{m}-\delta_{\text {peak }}\right) b h^{2}}
$$

where $L, b$ and $h$ are the span length, width and height of the specimen respectively; $\delta_{\text {peak }}$ is the deflection value corresponding to the peak load; and $L / m$ is the deflection at which the post-cracking strength value being calculated. The value of $m$ is a variable integer which depends on the application. The $A_{\text {post }, m}$ can be accounted by calculating the total area $\left(A_{\text {total,m }}\right)$ from point $\mathrm{O}$ until $\delta_{\text {post }}=L / \mathrm{m}$ and subtracting $A_{p r e}$ from it. The PCS value is a suitable indicator by which the flexural toughness and ductility of the beam or slab can be examined along the successive stages of post-cracking until failure by calculating and observing the variations of PCS values. In this paper, the PCS values are calculated and investigated for ECC slabs at deflection $L / 60$ to show the influence of the reinforcing index on the variation of $\mathrm{PCS}_{60}$ values in ECC slabs.

\section{Experimental program}

This program consists of establishing a timber mold with the dimension of $590 \mathrm{~mm} \times 220 \mathrm{~mm} \times 25 \mathrm{~mm}$ to cast and prepare ECC slabs. To evaluate the compressive strength for each slab, 4 cubes were cast with each slab having $100 \mathrm{~mm} \times 100 \mathrm{~mm} \times 100 \mathrm{~mm}$ as dimension. The ECC slabs were cured for 28 days inside water basin at the lab's temperature, whereas the ECC cubes were cured in the same basin for 7 days.

The main parameters used with the ECC slabs and cubes are: fiber content $\left(V_{f} \%\right)$, and reinforcing index $\left(V_{f} * l / d\right)$. The mechanical properties of polymer fibers are illustrated in Table 1.

As shown in Table 2,10 ECC slabs with their corresponding cubes were cast and prepared for testing using PVA RECS 15 fibers based on two different aspect ratios A.R. $=210$ (length $=8 \mathrm{~mm}$ ) and A.R. $=316$ (length $=12 \mathrm{~mm}$ ) respectively. With five fiber contents $V_{f}=1 \%, 1.5 \%, 2 \%, 2.5 \%, 3 \%$ for each aspect ratio. The ECC mix ratios and weight of ingredients per $1 \mathrm{~m}^{3}$ are illustrated in Table 3 . The cement type used was type I.Ordinary Portland cement (S.G. $=3.15$ ), fine silica sand with maximum size of particles equaling $200 \mu \mathrm{m}(\mathrm{S} . \mathrm{G} .=2.65)$, and fly ash type F (S.G. $=2.38)$ were used. Binder is considered as the sum weight of cement and fly ash. The superplasticizer (water reducer agent) used was Sika ${ }^{\star} V i s c o C r e t{ }^{\star} 1600$. For each mix, all dry materials were mixed in a rotating mixer for 3 min then the water with SP were added gradually and mixed for $5 \mathrm{~min}$ to attain an appropriate workability of 90 $150 \mathrm{~mm}$, as shown in Fig. 2a. In addition, Fig. 2b shows the fresh mix of ECC.

The testing of ECC slabs was conducted at age of 28 days using - INSTRON - displacement-controlled testing machine under third-point flexural loading with a displacement rate up to $0.005 \mathrm{~mm} / \mathrm{s}$. The span of $540 \mathrm{~mm}$ for slab was equally divided into 3 parts. A linear variable differential transformer (LVDT) was fixed at center of

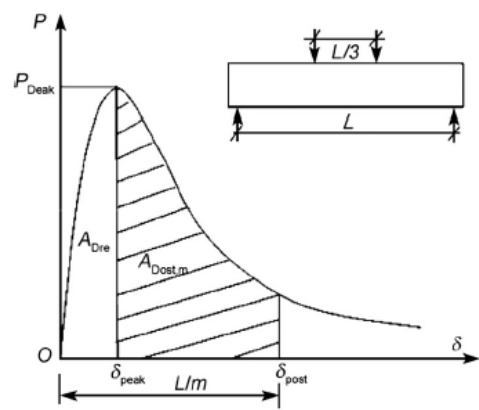

Fig. 1. Evaluation of toughness by determining post-cracking strength. 
Table 1

Mechanical properties of PVA fibers used in ECC specimens

\begin{tabular}{lllllllll}
\hline $\begin{array}{l}\text { Type of } \\
\text { fiber }\end{array}$ & $\begin{array}{l}\text { Grade of } \\
\text { fiber }\end{array}$ & $\begin{array}{l}\text { Specific } \\
\text { gravity }\end{array}$ & $\begin{array}{l}\text { Length of fiber } \\
(\mathrm{mm})\end{array}$ & $\begin{array}{l}\text { Diameter of fiber } \\
(\mu \mathrm{m})\end{array}$ & $\begin{array}{l}\text { Aspect ratio (A.R.) } \\
l / d\end{array}$ & $\begin{array}{l}\text { Elongation } \\
(\%)\end{array}$ & $\begin{array}{l}\text { Tensile strength } \\
(\mathrm{MPa})\end{array}$ & $\begin{array}{l}\text { Modulus of elasticity } \\
(\mathrm{GPa})\end{array}$ \\
\hline PVA & RECS15-8 & 1.3 & 8 & 38 & 210 & 7 & 1600 & 42 \\
& RECS15-12 & 1.3 & 12 & 38 & 316 & 7 & 1600 & 42 \\
\hline
\end{tabular}

Table 2

Reinforcing indices for different PVA fiber content and aspect ratio.

\begin{tabular}{|c|c|c|c|c|c|}
\hline Specimen & Symbol & Type & Aspect ratio A.R. $=l / d$ & Fiber content ${ }^{\mathrm{a}} V_{f} \%$ & Reinforcing index, R.I. $=V_{f} *(I / d)$ \\
\hline 1 & $\mathrm{PVA}_{1}$ & & & 1.0 & 210 \\
\hline 3 & $\mathrm{PVA}_{3}$ & RECS15-8 & 210 & 2.0 & 421 \\
\hline 4 & $\mathrm{PVA}_{4}$ & & & 2.5 & 527 \\
\hline 6 & $\mathrm{PVA}_{6}$ & & & 1.0 & 316 \\
\hline 7 & $\mathrm{PVA}_{7}$ & & & 1.5 & 474 \\
\hline 8 & $\mathrm{PVA}_{8}$ & RECS15-12 & 316 & 2.0 & 632 \\
\hline
\end{tabular}

a Determined by volume

the span for each slab to measure the deflection. Each test was continued until the load value descended below $25 \%$ of the ultimate value. Test results of load-deflection curves on ECC slabs are displayed in Figs. 3 and 4.

The testing of cubes for compressive strength was conducted at age of 7 days by ELE compression machine with rate of loading equal to $2.4 \mathrm{kN} / \mathrm{s}$. The results of compressive strength are displayed in Table 4

Direct tensile testing was conducted on PVA-ECC to evaluate the strain-hardening behavior with different fiber contents. The I-shaped specimens were cast and cured for 28 days and prepared for testing, as shown in Fig. $2 \mathrm{c}$ and d. The specimens were tested using $100 \mathrm{kN}$ capacity displacement-controlled universal testing machine. The results of direct tensile tests for different fiber contents are illustrated in Figs. 5 and 6.

\section{Results and discussion}

6.1. Compressive strength for ECC

The compressive strength results for ECC cubes are obtained at age of 7 days as illustrated in Table 4. Each magnitude recorded in this table is a mean of 4 cubes tested in ELE compressive test machine.

The aspect ratio is defined as the ratio of fiber length to its diameter. The value of aspect ratio of PVA fiber is highly influential due to its tiny diameter and thus, high value of aspect ratio. In order to account for the combined effect of fiber content and aspect ratio of used fiber, a suitable parameter was considered called "reinforcing index" which is the product of fiber content by its aspect ratio. For ECC PVA cubes, it can be observed from Fig. 7, as the reinforcing index value increases, the compressive strength gradually decreases. Thus, the relationship is nonlinear and almost seems to be nonlinear. The losses in compressive strength values are not significant about $15 \%$.

The results according to the variation of reinforcing index values state a superior fitness of 3rd order polynomial equation with significant correlation coefficient as indicated in Fig. 7.
6.2. ECC slabs

\subsubsection{First crack load}

First crack load results for ECC slabs are displayed in Fig. 8 it can be noticed from the first crack strength results that as the reinforcing index increases, the first crack load gradually decreases until the reinforcing index value of 790 . The decreasing tendency is sharp and the reduction is nearly $0.1 \mathrm{kN}$ per 100 of reinforcing index which is significant. After exceeding the value 790 until attaining the value of 948 , the first crack load begins to increase. The rate of increment is evident and more significant at reinforcing index 948 . This could be interpreted by increasing the reinforcing index up to the range of 790 , the fibers do not affect the first crack strength, and thus, the compressive strength values of ECCs dominate the trend of first crack strength values. However, by testing ECC PVA slab having reinforcing index exceeding 790, The PVA fibers will begin to take their role in affecting and dominating the first crack strength especially by accessing higher value of reinforcing index almost 1000 .

Again the regression analysis gives a linear fit with high value of correlation coefficient until reinforcing index value of 790 , as indicated in Fig. 8.

\subsubsection{Ultimate load at post-cracking}

It can be recognized from Fig. 8, according to the linear fit of ultimate load results at post-cracking stage for ECC PVA slabs, the general trend of these results seems to be directly proportional to reinforcing index value with a small rate of increment nearly about $0.04 \mathrm{kN}$ per 100 of reinforcing index. The results obtained show a drop in the general trend of ultimate load at post-cracking in two samples. This could be attributed to the degree of dispersion of fibers. As the fiber content or aspect ratio increases, the fresh matrix suffers a difficulty in dispersing the PVA fibers which in

Table 3

Mix proportion used in ECC specimens.

\begin{tabular}{lllll}
\hline Cement C/C & Sand S/C & Fly ash FA/C & Water W/B & $($ SP/B)\% \\
\hline $1(820)$ & $0.8(656)$ & $0.25(205)$ & $0.37(379.25)$ & $0.3-0.35(3.075-3.588)$ \\
\hline
\end{tabular}

B - Binder i.e. cement and fly ash.

() - by weight in $\mathrm{kg} / \mathrm{m}^{3}$. 

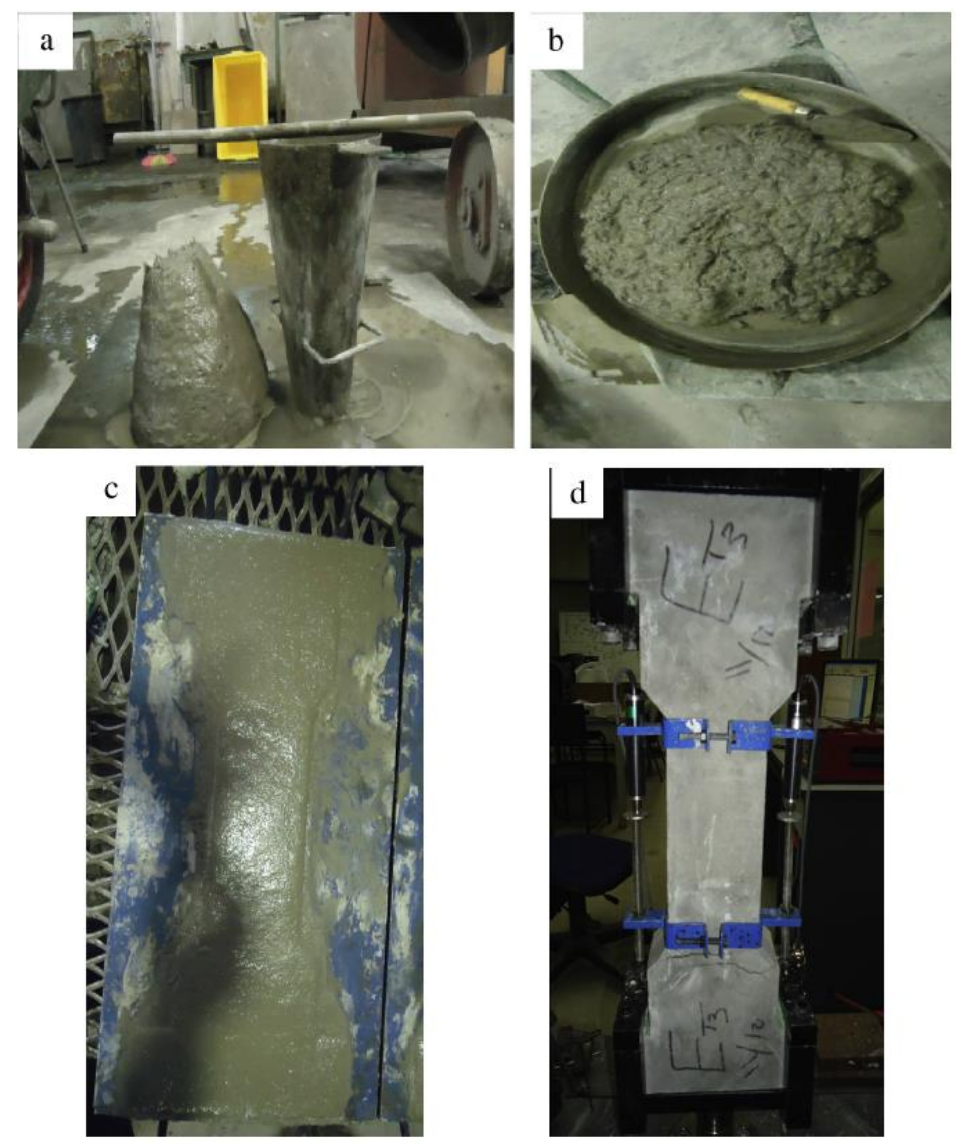

Fig. 2. (a) Slump test for ECC mix, (b) fresh ECC, (c) I-shaped tensile specimen after casting, and (d) I-shaped specimen under direct tensile loading.

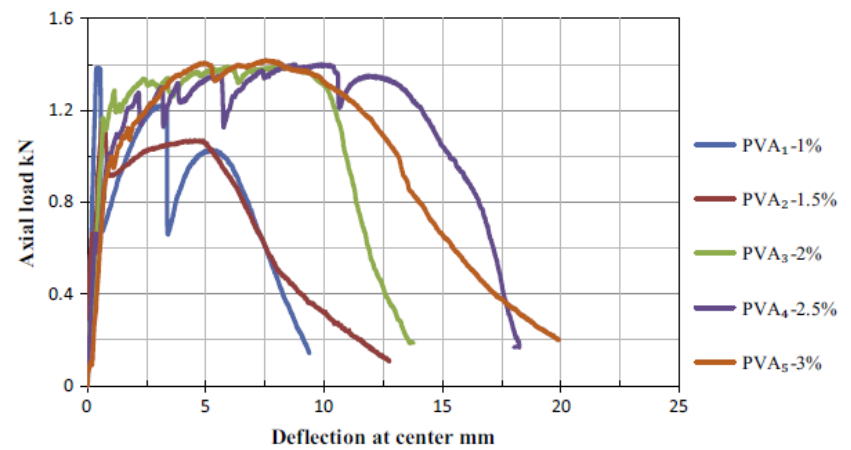

Fig. 3. Load-deflection relationship for PVA ECC slabs reinforced with PVA-RECS15-8 mm, A.R. = 210 .

turn results in low workability and less homogeneity of matrix. Increase in PVA fiber content results in undesirable orientation of fibers which leads to a slight increase in post cracking strength and occasionally, a drop in post cracking strength.
Regarding Fig. 9, Results also indicate that the first three ECC PVA slabs of reinforcing indices 210 and 316, behave in a softening tail of load-deflection curve after the occurrence of first crack that is, the post cracking strength is less than its first crack load value. 


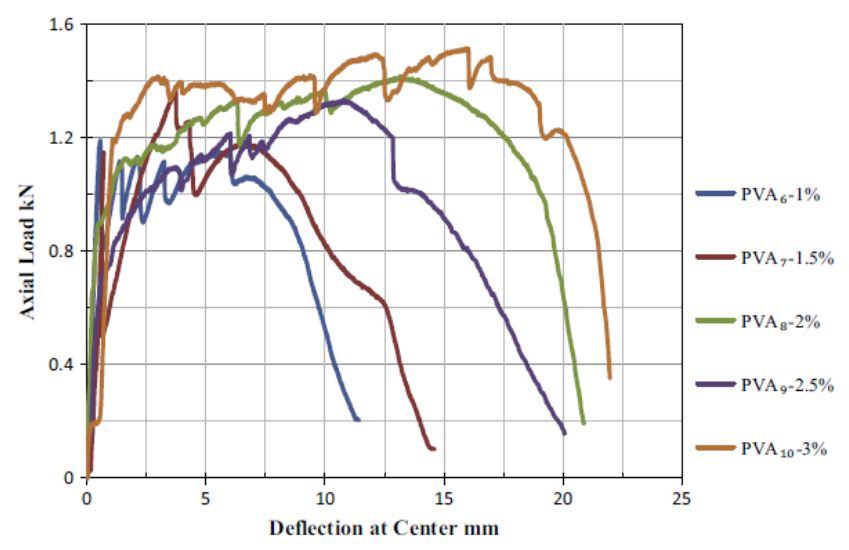

Fig. 4. Load-deflection relationship for PVA ECC slabs reinforced with PVA-RECS15-12 mm, A.R. = 316 .

Table 4

Compressive and flexural testing values obtained for ECC cubes and slabs.

\begin{tabular}{|c|c|c|c|c|c|c|c|}
\hline $\begin{array}{l}\text { Symbol of } \\
\text { specimen }\end{array}$ & $\begin{array}{l}\text { Reinforcing Index } \\
\text { R.I. }=V_{f} *(l / d)\end{array}$ & $\begin{array}{l}\text { Average compressive } \\
\text { strength }(\mathrm{MPa})\end{array}$ & $\begin{array}{l}\text { Max. axial load at } \\
\text { first cracking }(\mathrm{kN})\end{array}$ & $\begin{array}{l}\text { Ultimate load at } \\
\text { post-cracking }(\mathrm{kN})\end{array}$ & $\begin{array}{l}\text { Deflection at first } \\
\text { crack }(\mathrm{mm})\end{array}$ & $\begin{array}{l}\text { Deflection at } \\
\text { ultimate load (mm) }\end{array}$ & $\begin{array}{l}\text { Deflection at } \\
\text { failure }(\mathrm{mm})\end{array}$ \\
\hline $\mathrm{PVA}_{1}$ & 210 & 62.98 & 1.384 & 1.222 & 0.387 & 3.15 & 8.67 \\
\hline $\mathrm{PVA}_{6}$ & 316 & 58.49 & 1.190 & 1.150 & 0.550 & 5.59 & 10.60 \\
\hline $\mathrm{PVA}_{2}$ & 316 & 54.56 & 1.148 & 1.068 & 0.637 & 4.89 & 10.58 \\
\hline $\mathrm{PVA}_{3}$ & 421 & 51.44 & 1.166 & 1.391 & 0.662 & 7.96 & 12.56 \\
\hline $\mathrm{PVA}_{7}$ & 474 & 50.94 & 1.147 & 1.377 & 0.698 & 3.70 & 13.35 \\
\hline $\mathrm{PVA}_{4}$ & 527 & 50.50 & 1.000 & 1.398 & 0.867 & 10.20 & 17.70 \\
\hline $\mathrm{PVA}_{5}$ & 631 & 50.20 & 0.974 & 1.420 & 0.950 & 8.50 & 18.50 \\
\hline $\mathrm{PVA}_{B}$ & 632 & 50.12 & 0.900 & 1.415 & 0.506 & 13.93 & 20.62 \\
\hline $\mathrm{PVA}_{9}$ & 790 & 48.03 & 0.754 & 1.334 & 0.850 & 11.00 & 18.90 \\
\hline $\mathrm{PVA}_{10}$ & 948 & 47.31 & 1.166 & 1.514 & 1.050 & 15.96 & 21.70 \\
\hline
\end{tabular}

Eventually, a localization of first crack occurs. On the other hand, the behavior of the rest of slabs is characterized by strain hardening and multiple cracking features that is, they sustain an ultimate load more than the first crack load and develop subsequent multiple cracks due to the fiber mechanism-bridging action.

It can be observed from Fig. 10 that the ultimate load results at post-cracking are highly scattered and the linear fit presents low correlation coefficient.

\subsubsection{First crack deflection}

From Fig. 10, according to the linear fit of first crack deflection results, it can be recognized that by increasing the reinforcing index value, there is a slight increase in first crack deflection values of ECC PVA slabs, and the increment rate is about $0.08 \mathrm{~mm}$ per 100 of reinforcing index. This result indicates that the ECC PVA material tends to be more elastic with a slight decrease in modulus of elasticity as the reinforcing index increases. Moreover, the linear fit for first crack deflection results seems to be more suitable despite the low correlation coefficient.

\subsubsection{Deflection at ultimate load}

For the ECC PVA slabs, as the reinforcing index increases, the deflection value at ultimate load also increases as shown in Fig. 10. In other words, the increase in reinforcing index provides better ductility as well as improves ECC slabs ability to bend more before failure. The regression analysis of deflection results at ultimate load for ECC PVA slabs is set to be linear fit with a medium correlation coefficient and increment rate of $1.64 \mathrm{~mm}$ for each
100 of reinforcing index which is able to improve the ductility of ECC slabs to acceptable limits.

\subsubsection{Deflection at failure}

Deflection at failure value for each ECC slab was measured according to the corresponding deflection value of $25 \%$ of ultimate load at post-cracking specified at the descending part of loaddeflection curve. It can be noticed from Fig. 10 that the trend of deflection at failure values is likely to be almost similar to the trend of deflection values at ultimate load performing higher values. Furthermore, the linear fit analysis for these results is found more suitable. The increment rate determined from fit analysis is $1.87 \mathrm{~mm}$ per 100 of reinforcing index which is slightly more than the increment rate of deflection at ultimate load, with better correlation coefficient value.

6.2.6. Behavior of load-deflection curve and nature of cracks

For slab $\mathrm{PVA}_{1}, \mathrm{PVA}_{2}$ and $\mathrm{PVA}_{6}$ since the value of reinforcing index is not sufficient to sustain higher loads at post-cracking stage, the strain-hardening behavior cannot be recognized in these specimens and the behavior of slabs seems to be within a narrow field with less deflection at failure which denotes a limited ductility as well as less capacity of energy absorption as shown in Figs. 3, 4 and 9. In addition, small numbers of cracks can be recognized in the middle third of the slab after failure. Furthermore, few bridging of cracks could be observed through the path of the load-deflection curve; after the first crack, the curve descends gradually and softens due to the widening and localization of initiating crack. Regarding the rest of ECC PVA slabs and starting from the reinforcing index 421 , 


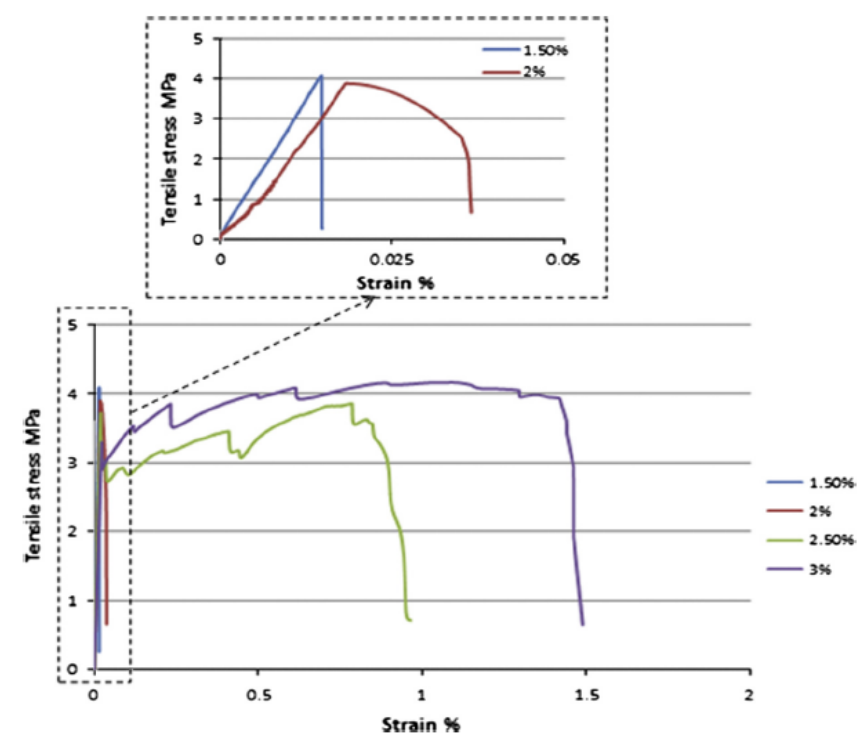

Fig. 5. Direct tensile stress-strain relationship for ECC I-shaped samples reinforced with PVA RECS15-8 mm, A.R. = 210 .

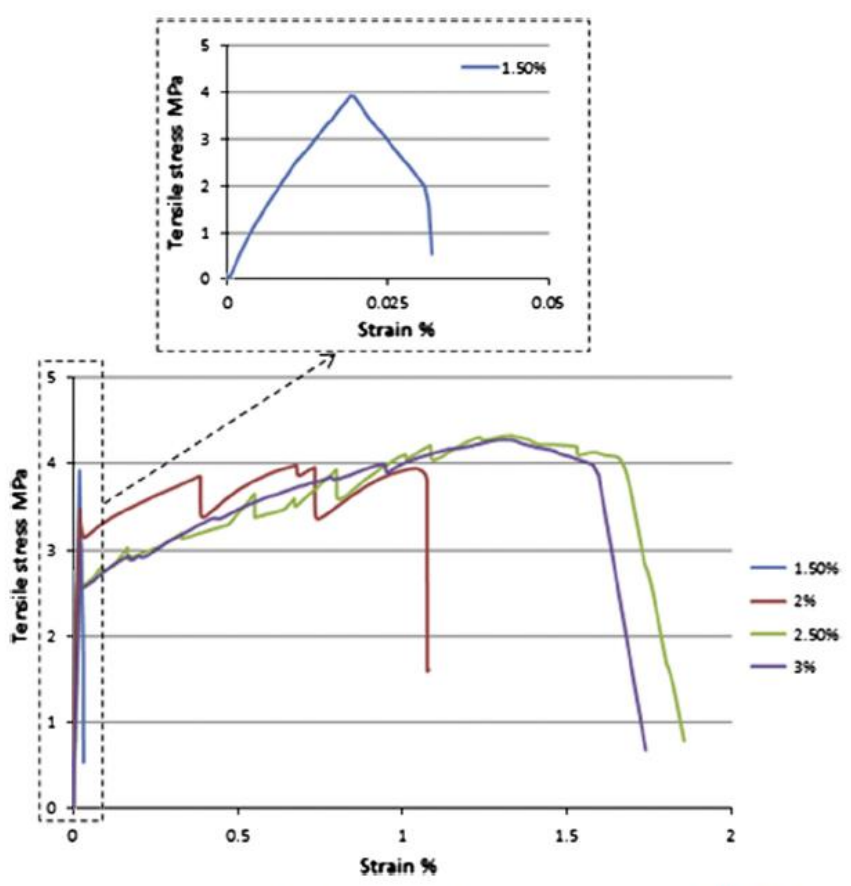

Fig. 6. Direct tensile stress-strain relationship for ECC I-shaped samples reinforced with PVA RECS15-12 mm, A.R. = 316

strain-hardening and multiple cracking behaviors are observed. Subsequent and successive bridging of cracks appear through the path of load-deflection curve at post-cracking stage of loading process, within the field starting from first crack point until the onset of descending of load-deflection curve. This behavior characterized with relatively high deflection values at failure denotes high ductility and high energy absorption capacity. Moreover, the bridging action of PVA fibers will develop the ultimate strength of slab upon 


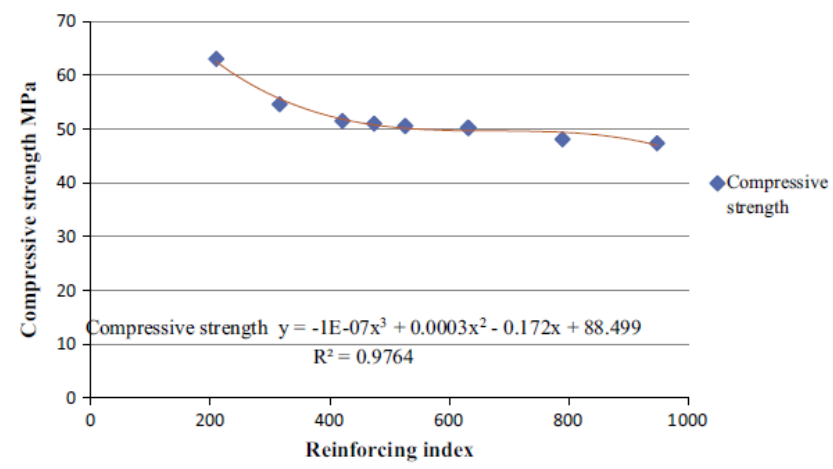

Fig. 7. Effect of reinforcing index on compressive strength of ECC.

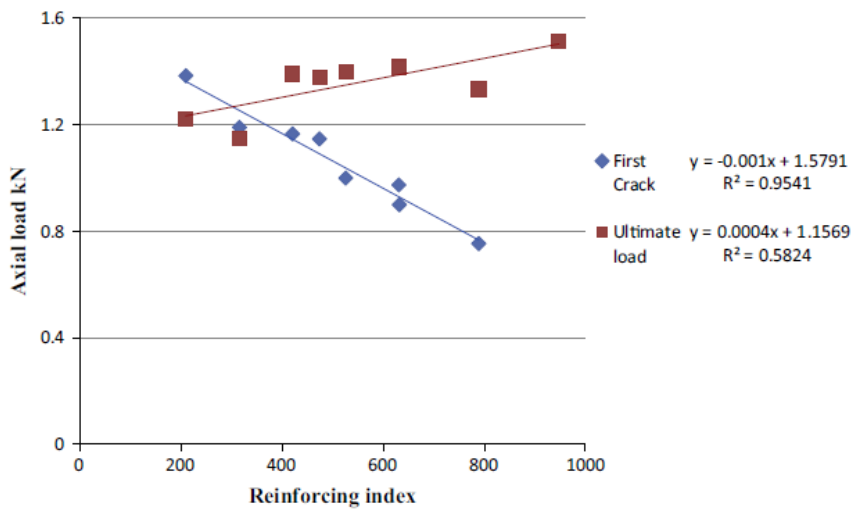

Fig. 8. Effect of reinforcing index on first crack load and axial load.

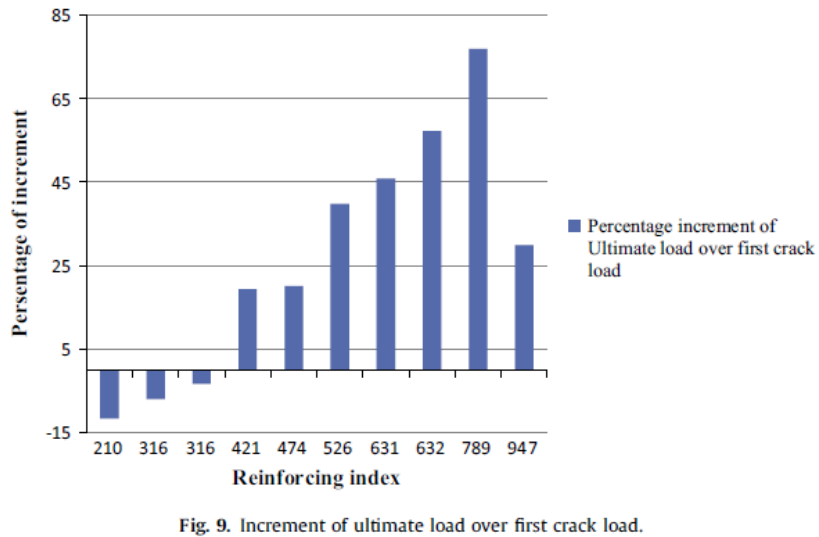

the first crack strength as shown in Fig. 9. However, the descending part of load-deflection curve shows a steep slope until failure. Despite the distinct behavior of ECC PVA slabs, the desired values of deflection were not achieved. Thus, the ECC PVA slabs did not attain the desired ductility due to the rupture of PVA fibers at failure. To explain this behavior, it is convenient to know that the PVA fibers generate high chemical bond with cement hydrates. At failure, the PVA fibers will rupture instead of bond-slip failure (that

\section{Link to Full-Text Articles :}

http://www.sciencedirect.com/science/article/pii/S0950061814011805 